\title{
Is age-related decline in lean mass and physical function accelerated by obstructive lung disease or smoking?
}

\author{
Bram van den Borst, ${ }^{1,2}$ Annemarie Koster, ${ }^{2}$ Binbing Yu, ${ }^{2}$ Harry R Gosker, ${ }^{1}$ \\ Bernd Meibohm, ${ }^{3}$ Douglas C Bauer, ${ }^{4}$ Stephen B Kritchevsky, ${ }^{5}$ Yongmei Liu, ${ }^{6}$ \\ Anne B Newman, ${ }^{7}$ Tamara B Harris, ${ }^{2}$ Annemie M W J Schols, ${ }^{1}$ For the Health ABC \\ Study
}

\section{See Editorial, p 933}

- Additional tables are published online only. To view these files please visit the journal online (http://thorax.bmj. com)

${ }^{1}$ Department of Respiratory Medicine, NUTRIM School for Nutrition, Toxicology and Metabolism, Maastricht University Medical Center+ Maastricht, The Netherlands 2Laboratory of Epidemiology Demography and Biometry. National Institute on Aging, Bethesda, Maryland, USA ${ }^{3}$ Department of Pharmaceutical Sciences, University of Tennessee Health Science Center, Memphis, Tennessee, USA

${ }^{4}$ Division of General Internal Medicine, University of California, San Francisco, California, USA

${ }^{5}$ Sticht Center on Aging, Wake Forest University,

Winston-Salem, North Carolina, USA

${ }^{6}$ Department of Epidemiology and Prevention, Division of Public Health Sciences, Wake Forest University School of Medicine, Winston-Salem, North Carolina, USA

${ }^{7}$ Department of Epidemiology, Graduate School of Public Health, University of Pittsburgh, Pittsburgh, Pennsylvania, USA

\section{Correspondence to}

Dr Bram van den Borst, Department of Respiratory Medicine, NUTRIM School for Nutrition, Toxicology and Metabolism, Maastricht University Medical Center+ P 0 Box 616, $6200 \mathrm{MD}$

Maastricht, The Netherlands; b.vdborst@

maastrichtuniversity.n

Received 10 February 2011 Accepted 9 June 2011

Published Online First

1 July 2011

\begin{abstract}
Background and aims Cross-sectional studies suggest that obstructive lung disease (OLD) and smoking affect lean mass and mobility. A study was undertaken to investigate whether OLD and smoking accelerate the ageing-related decline in lean mass and physical functioning.
\end{abstract}

Methods 260 patients with OLD (mean \pm SD forced expiratory volume in $1 \mathrm{~s}\left(\mathrm{FEV}_{1}\right) 63 \pm 18 \%$ predicted), 157 smoking controls ( $\mathrm{FEV}_{1} 95 \pm 16 \%$ predicted), 866 formersmoking controls ( $\mathrm{FEV}_{1} 100 \pm 16 \%$ predicted) and 891 never-smoking controls ( $\mathrm{FEV}_{1} 104 \pm 17 \%$ predicted) participating in the Health, Aging and Body Composition (ABC) Study were studied. At baseline the mean age was $74 \pm 3$ years and participants reported no functional limitations. Baseline and 7-year longitudinal data of body composition (by dual-energy x-ray absorptiometry), muscle strength (by hand and leg dynamometry) and Short Physical Performance Battery (SPPB) were investigated.

Results Compared with never-smoking controls, patients with OLD and smoking controls had a significantly lower weight, fat mass, lean mass and bone mineral content (BMC) at baseline $(p<0.05)$. While the loss of weight, fat mass, lean mass and strength was comparable between patients with OLD and neversmoking controls, the SPPB declined 0.12 points/year faster in men with OLD $(p=0.01)$ and BMC declined $4 \mathrm{~g} /$ year faster in women with OLD $(p=0.02)$. In smoking controls only lean mass declined $0.1 \mathrm{~kg} /$ year faster in women $(p=0.03)$ and BMC $8 \mathrm{~g} /$ year faster in men $(p=0.02)$ compared with never-smoking controls.

Conclusions Initially well-functioning older adults with mild-to-moderate OLD and smokers without OLD have a comparable compromised baseline profile of body composition and physical functioning, while 7-year longitudinal trajectories are to a large extent comparable to those observed in never-smokers without OLD. This suggests a common insult earlier in life related to smoking.

\section{INTRODUCTION}

Chronic obstructive pulmonary disease (COPD) affects approximately $14 \%$ of older adults and is related to increased immobility, hospitalisations and resulting healthcare costs. ${ }^{1}$ It is characterised by irreversible airflow limitation and is associated with an abnormal inflammatory response of the

\section{Key messages}

What is the key question?

- Is age-related decline in lean mass and physical function accelerated by Obstructive Lung Disease (OLD) or smoking?

What is the bottom line?

- Older adults with mild-to-moderate OLD and smokers without OLD have a comparable compromised baseline profile of body composition and physical functioning, while seven-year longitudinal trajectories are to a large extent comparable to those observed in never-smokers without OLD.

- This suggests a common insult earlier in life related to smoking.

Why read on?

- This is the first study analyzing the seven-year longitudinal pattern of body composition changes and the decline in physical functioning simultaneously in older adults with Obstructive Lung Disease (OLD) and in smokers without OLD in comparison with ageing effects in a neversmoking control group without OLD.

lungs mainly to cigarette smoke. ${ }^{2}$ It has been increasingly recognised as a disease with marked extrapulmonary manifestations such as muscle wasting and weakness, osteoporosis and cardiovascular disease, ${ }^{3}$ in which systemic inflammation is thought to play an important role. ${ }^{4}$ It remains unclear, however, if these systemic manifestations are comorbid conditions related to a common noxious exposure or if these are systemic consequences of the disease itself.

To date, skeletal muscle weakness and wasting are the most studied and established extrapulmonary determinants of impaired mobility and increased mortality in COPD. ${ }^{6}$ Putative pathophysiological mechanisms of altered body composition and physical functioning in COPD have originated from cross-sectional studies ${ }^{7-10}$ and from longitudinal case studies without appropriate control groups. ${ }^{11-14}$ However, since changes in body composition and dysregulation of inflammation are also common with ageing, ${ }^{15}{ }^{16}$ and since 
studied COPD populations often consist of older adults (60+ years), inclusion of matched non-COPD control groups is crucial to unravel the effect of airflow obstruction on the pattern and progression of changes in body composition and physical function as well as the potential modulating role of systemic inflammatory markers. To our knowledge, such studies are currently lacking. Cross-sectional studies in healthy smokers have suggested detrimental effects of smoking on skeletal muscle function. ${ }^{17}{ }^{18}$ Increased systemic levels of proinflammatory markers were observed in healthy smokers ${ }^{19}$ but also in former smokers. ${ }^{20}$ Collectively, these data suggest that, in the absence of chronic airflow limitation, smoking may enhance skeletal muscle wasting and accelerate the decline in physical functioning, and that systemic inflammation could be a modulator.

We hypothesised that older adults with obstructive lung disease (OLD) and smokers with normal lung function have accelerated loss of lean mass and physical functioning compared with a population of never-smokers. Systemic inflammatory markers could contribute to the association with body composition and physical functioning. We therefore examined 7-year longitudinal changes in body composition and physical functioning in older persons with OLD and in a non-OLD population stratified by smoking status.

\section{METHODS}

\section{Study population}

This study was performed in persons participating in the Health, Aging and Body Composition (Health $\mathrm{ABC}$ ) study. This is a longitudinal study of 3075 well-functioning black and white men and women aged 70-79 years residing in and near Pittsburgh, Pennsylvania and Memphis, Tennessee. Baseline data were obtained in 1997/8 through in-person interview and clinicbased examination. Inclusion criteria were no reported difficulty in walking a quarter of a mile, climbing 10 steps without resting or performing mobility-related activities of daily living. Exclusion criteria were any life-threatening condition, participation in any research study involving medications or modification of eating or exercise habits, plans to move from the geographical area within 3 years and difficulty in communicating with the study personnel or cognitive impairment. The Health $A B C$ study protocol was approved by the Institutional Review Boards of the clinical sites. Written informed consent was obtained for all participants. The current study presents an analysis of the Health $\mathrm{ABC}$ dataset using 7-year follow-up data from participants who met the criteria for OLD $(n=260)$ and control participants with normal lung function $(n=1914)$. Participants with missing body composition measures at baseline and those with no measures of systemic inflammatory markers were excluded (figure 1).

\section{Measures}

\section{Lung function, smoking status and smoking history}

Lung function was assessed according to international standards as previously reported. ${ }^{10}$ OLD was defined at baseline as reduced (ie, less than the lower limit of normal (LLN)) forced expiratory volume in $1 \mathrm{~s}\left(\mathrm{FEV}_{1}\right) /$ forced vital capacity $(\mathrm{FVC})$ as determined by age, sex and race-normalised values. ${ }^{10} 2122$ Cigarette smoking status (smoker, former-smoker, never-smoker) was recorded based on self-report. At baseline, smokers, former-smokers and never-smokers without OLD (ie, $\mathrm{FEV}_{1} / \mathrm{FVC} \geq \mathrm{LLN}$ ) were designated as smoking controls, formerly-smoking controls and neversmoking controls, respectively. Participants with restrictive lung disease $\left(\mathrm{FEV}_{1} / \mathrm{FVC} \geq \mathrm{LLN}\right.$ but $\left.\mathrm{FVC}<\mathrm{LLN}\right)$ were excluded. At

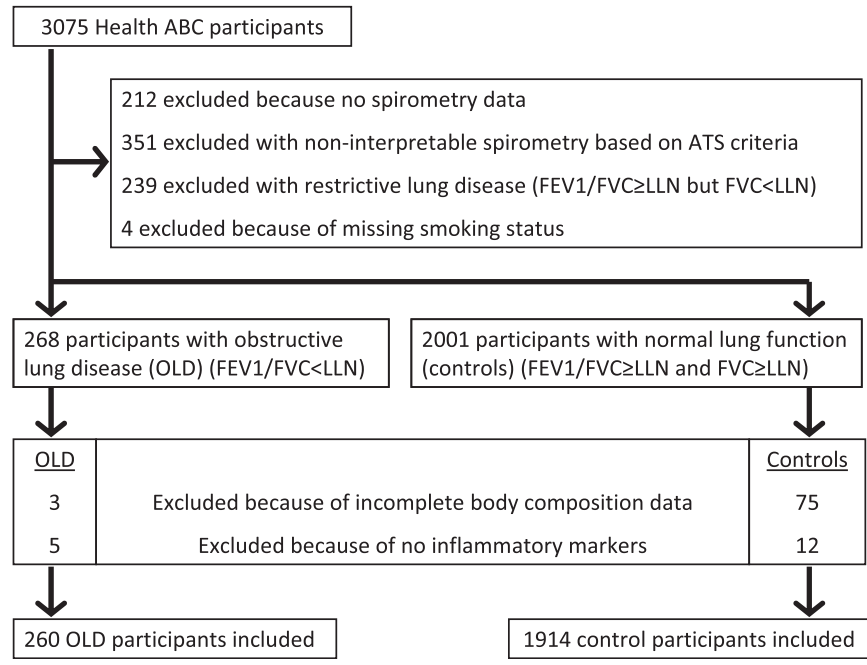

Figure 1 Flow chart of participant selection at baseline. ATS, American Thoracic Society; FEV $_{1}$, forced expiratory volume in $1 \mathrm{~s}$; FVC, forced vital capacity; LLN, lower limit of normal; OLD, obstructive lung disease.

baseline the number of pack-years smoked (1 pack-year $=20$ cigarettes/day for 1 year) was obtained based on self-report.

Lung function was repeated in years 5 and 8 . Participants with valid lung function measures both at baseline and in years 5 and/ or 8 were included in the analysis of lung function decline. Consequently, lung function decline could be analysed in 1658 participants over a mean (SD) period of 6.2 (1.3) years, including $2.6(0.5)$ valid measurements per participant.

\section{Body composition}

Height was measured using a wall-mounted stadiometer. Body weight was assessed to the nearest $0.1 \mathrm{~kg}$ using a standard balance beam scale and body mass index (BMI) was calculated as weight/height ${ }^{2}\left(\mathrm{~kg} / \mathrm{m}^{2}\right)$. Weight was measured in years 1-6 and 8 . Whole body dual energy x-ray absorptiometry (DXA, Hologic 4500A software Version 8.21, Waltham, Massachusetts, USA) was applied to retrieve whole body fat mass, lean mass, leg lean mass (left and right leg were summed) and bone mineral content (BMC). DXA measurements were performed in years $1-6$ and 8.

\section{Muscle function and mobility}

In years 1, 2, 4, 6 and 8, maximal isokinetic strength of the quadriceps muscle was assessed by a Kin-Com 125 AP Dynamometer (Chattanooga, Tennessee, USA) at $60 \%$ s. The right leg was tested unless there was a contraindication. The maximum torque was taken from three reproducible and acceptable trials. Participants with a systolic blood pressure $\geq 200 \mathrm{~mm} \mathrm{Hg}$ or a diastolic blood pressure $\geq 110 \mathrm{~mm} \mathrm{Hg}$ or who reported a history of cerebral aneurysm, cerebral bleeding, bilateral total knee replacement or severe bilateral knee pain were excluded from testing (12.7\% of the original cohort). ${ }^{15}$ As a consequence, baseline measures for quadriceps strength were available for 228 participants with OLD and 1730 controls. Hand grip strength was measured using a Jamar Hydraulic Hand Dynamometer at baseline and in years 2, 4, 6 and 8 . The maximum values of the right and left hands were summed from two trials. In years 1, 4 and 6, lower extremity function was assessed using the Short Physical Performance Battery (SPPB). ${ }^{23}{ }^{24}$ The battery consists of a test of gait speed, standing balance and time to rise from 
Table 1 Baseline characteristics of men in the Health ABC Study according to obstructive lung disease (OLD) status and smoking status

\begin{tabular}{|c|c|c|c|c|c|c|}
\hline & $\begin{array}{l}\text { OLD } \\
(n=150) \\
A\end{array}$ & $\begin{array}{l}\text { Smoking controls } \\
(\mathrm{n}=74) \\
\mathrm{B}\end{array}$ & $\begin{array}{l}\text { Formerly- smoking } \\
\text { controls }(n=534) \\
\text { C }\end{array}$ & $\begin{array}{l}\text { Never-smoking } \\
\text { controls }(\mathrm{n}=301) \\
\text { D }\end{array}$ & $\begin{array}{l}\text { Overall } \\
\text { p value }\end{array}$ & $\begin{array}{l}\text { Significant post hoc } \\
\text { comparisons* }\end{array}$ \\
\hline \multicolumn{7}{|l|}{ Demographics } \\
\hline Race, \% white & 52 & 35 & 70 & 65 & $<0.001$ & $A C, B C, B D$ \\
\hline Site, \% Memphis & 60 & 50 & 47 & 51 & 0.013 & $A C, A D$ \\
\hline $\begin{array}{l}\text { Physical activity, } \\
\mathrm{kcal} / \mathrm{kg} / \text { week } \dagger\end{array}$ & $68(37-105)$ & $59(35-125)$ & $67(40-114)$ & $72(39-114)$ & 0.68 & - \\
\hline Depression, \% & 7 & 1 & 8 & 5 & 0.22 & - \\
\hline Cardiovascular disease, \% & 25 & 24 & 30 & 23 & 0.10 & - \\
\hline Diabetes, $\%$ & 13 & 15 & 16 & 15 & 0.91 & - \\
\hline Oral steroid use, $\%$ & 1 & 1 & 2 & 0 & 0.49 & - \\
\hline Calcium supplementation, \% & 5 & 7 & 7 & 9 & 0.35 & - \\
\hline Vitamin D supplementation, \% & 3 & 1 & 3 & 4 & 0.63 & - \\
\hline Pack-years, n† & $48(26-64)$ & $48(27-60)$ & $25(10-41)$ & $0(0)$ & $<0.001$ & $A C, A D, B C, B D, C D$ \\
\hline \multicolumn{7}{|l|}{ Systemic inflammatory markers } \\
\hline IL-6, pg/ml† & $2.23(1.59-3.58)$ & $2.46(1.62-3.91)$ & $1.74(1.18-2.70)$ & $1.68(1.18-2.32)$ & $<0.001$ & $A C, A D, B D$ \\
\hline $\mathrm{CRP}, \mu \mathrm{g} / \mathrm{ml} \dagger$ & $2.00(1.21-3.51)$ & $1.54(0.92-3.30)$ & $1.34(0.88-2.39)$ & $1.30(0.89-2.22)$ & $<0.001$ & $A C, A D$ \\
\hline TNF- $\alpha, \mathrm{pg} / \mathrm{ml} \dagger$ & $3.13(2.41-4.32)$ & $3.18(2.34-4.37)$ & $3.34(2.59-4.26)$ & $3.05(2.43-4.00)$ & 0.23 & - \\
\hline
\end{tabular}

Data are mean (SD) unless specified otherwise.

${ }^{*}$ Corrected for multiple testing.

tMedian (IQR).

$\ddagger$ From reference equations. $^{21}$

CRP, C reactive protein; FEV ${ }_{1}$, forced expiratory volume in $1 \mathrm{~s}$; FVC, forced vital capacity; IL-6, interleukin 6 ; SPPB, short physical performance battery; TNF- $\alpha$, tumour necrosis factor $\alpha$.

a chair five times. Each item was scored using a 5-point scale $(0=$ inability to complete test, $4=$ highest level of performance) leading to a combined $0-12$-point summary scale.

\section{Inflammatory markers}

At baseline, measures of the cytokines interleukin 6 (IL-6), tumour necrosis factor $\alpha$ (TNF- $\alpha$ ) and C reactive protein (CRP)

Table 2 Baseline characteristics of women in the Health ABC Study according to obstructive lung disease (OLD) status and smoking status

\begin{tabular}{|c|c|c|c|c|c|c|}
\hline & $\begin{array}{l}\text { OLD } \\
(n=110) \\
A\end{array}$ & $\begin{array}{l}\text { Smoking } \\
\text { controls }(n=83) \\
\text { B }\end{array}$ & $\begin{array}{l}\text { Formerly-smoking } \\
\text { controls }(n=332) \\
\text { C }\end{array}$ & $\begin{array}{l}\text { Never-smoking } \\
\text { controls }(n=590) \\
\text { D }\end{array}$ & $\begin{array}{l}\text { Overall } \\
\text { p value }\end{array}$ & $\begin{array}{l}\text { Significant post } \\
\text { hoc comparisons* }\end{array}$ \\
\hline \multicolumn{7}{|l|}{ Demographics } \\
\hline Age, years & $72.8(2.8)$ & $73.7(3.0)$ & $73.3(2.8)$ & $73.5(2.9)$ & 0.06 & - \\
\hline Race, \% white & 62 & 37 & 56 & 59 & 0.001 & $A B, B C, B D$ \\
\hline Site, \% Memphis & 42 & 43 & 46 & 51 & 0.11 & - \\
\hline $\begin{array}{l}\text { Physical activity, } \\
\mathrm{kcal} / \mathrm{kg} / \text { week } \dagger\end{array}$ & $67(36-91)$ & $66(36-107)$ & $65(40-97)$ & $74(45-113)$ & 0.006 & $\mathrm{CD}$ \\
\hline \multicolumn{7}{|c|}{ Comorbidity, steroid use, calcium and vitamin D supplementation } \\
\hline Depression, \% & 12 & 16 & 11 & 11 & 0.70 & - \\
\hline Cardiovascular disease, \% & 18 & 27 & 22 & 17 & 0.42 & - \\
\hline Diabetes, \% & 10 & 15 & 11 & 13 & 0.63 & - \\
\hline Oral steroid use, $\%$ & 9 & 2 & 3 & 2 & 0.001 & $A D$ \\
\hline Calcium supplementation, \% & 27 & 24 & 29 & 32 & 0.35 & - \\
\hline Vitamin D supplementation, \% & 9 & 7 & 13 & 15 & 0.10 & - \\
\hline \multicolumn{7}{|l|}{ Lung function and smoking } \\
\hline $\mathrm{FEV}_{1}, \%$ predicted $\ddagger$ & $65(19)$ & $97(19)$ & $101(18)$ & $104(18)$ & $<0.001$ & $A B, A C, A D, B D, C D$ \\
\hline $\mathrm{FEV}_{1}, \mathrm{I}$ & $1.24(0.38)$ & $1.66(0.33)$ & $1.87(0.38)$ & $1.95(0.36)$ & $<0.001$ & $A B, A C, A D, B C, B D, C D$ \\
\hline $\mathrm{FEV}_{1} / \mathrm{FVC}$, ratio & $58(7)$ & $75(6)$ & $76(5)$ & $77(5)$ & $<0.001$ & $A B, A C, A D, B D, C D$ \\
\hline Pack-years, n† & $20(0-51)$ & $29(19-50)$ & $15(5-38)$ & $0(0)$ & $<0.001$ & $A B, A D, B C, B D, C D$ \\
\hline \multicolumn{7}{|l|}{ Systemic inflammatory markers } \\
\hline IL-6, pg/ml† & $1.90(1.31-2.86)$ & $1.92(1.33-2.83)$ & $1.71(1.17-2.53)$ & $1.63(1.12-2.46)$ & 0.021 & $\mathrm{BC}$ \\
\hline $\mathrm{CRP}, \mu \mathrm{g} / \mathrm{ml} \dagger$ & $2.09(1.07-3.72)$ & $2.00(1.17-3.95)$ & $2.18(1.27-3.83)$ & $1.63(0.95-3.07)$ & $<0.001$ & $\mathrm{CD}$ \\
\hline TNF- $\alpha, \mathrm{pg} / \mathrm{ml} \dagger$ & $2.92(2.17-3.75)$ & $3.06(2.19-3.95)$ & $3.02(2.37-3.86)$ & $3.10(2.30-3.97)$ & 0.63 & - \\
\hline
\end{tabular}

Data are mean (SD) unless specified otherwise.

${ }^{*}$ Corrected for multiple testing.

tMedian (IQR).

fFrom reference equations. ${ }^{21}$

CRP, C reactive protein; FEV 1 , forced expiratory volume in $1 \mathrm{~s}$; FVC, forced vital capacity; IL-6, interleukin 6 ; SPPB, short physical performance battery; TNF- $\alpha$, tumour necrosis factor $\alpha$. 
Figure 2 Baseline characteristics of body composition and physical functioning in men and women. Data are mean \pm SE. ${ }^{*} \mathrm{p}<0.05$. OLD, obstructive lung disease; SPPB, Short Physical Performance Battery.
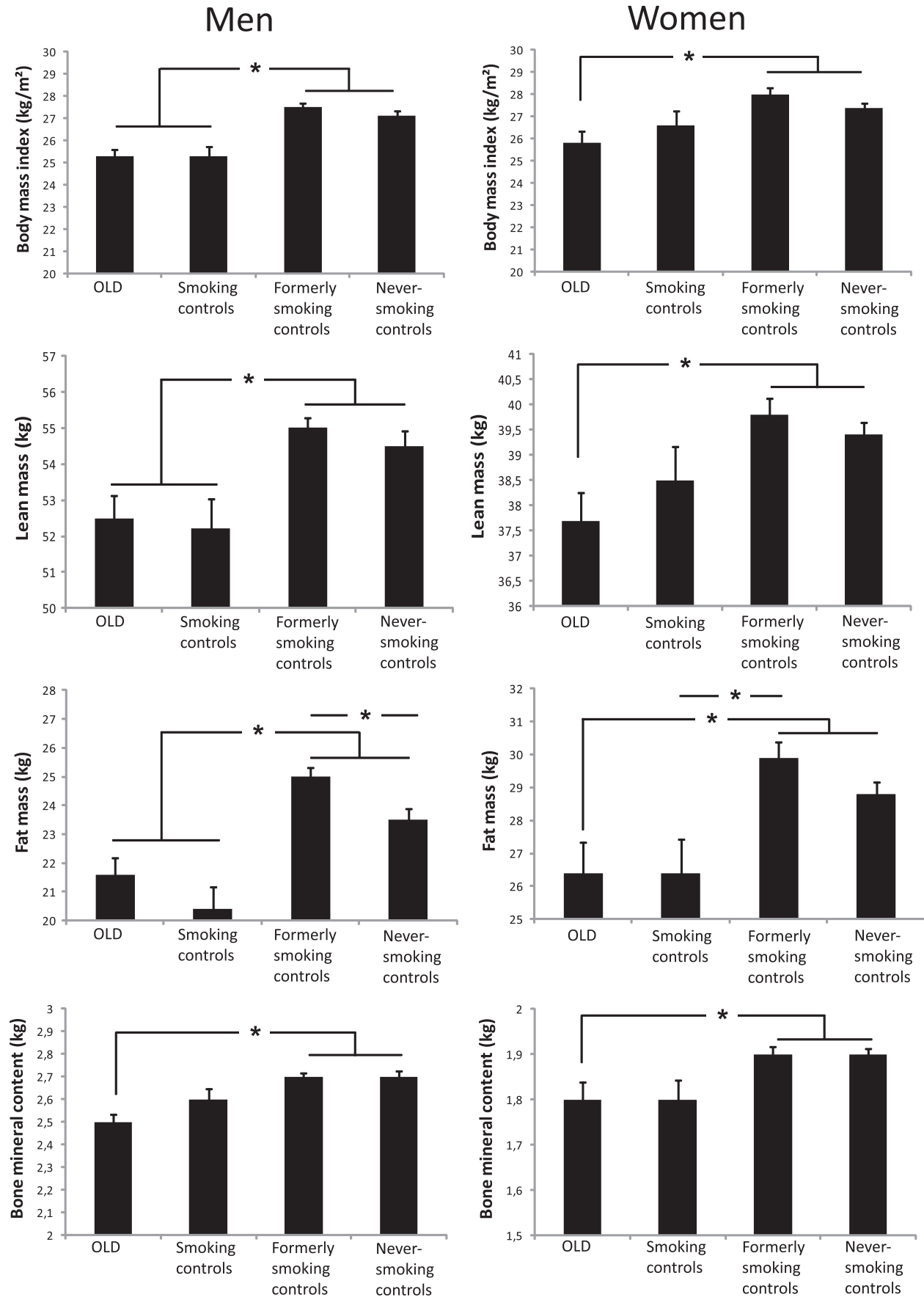

were obtained from frozen stored plasma or serum (see Koster et $a l^{25}$ for further details).

\section{Covariates}

At baseline, clinic site, age, race (black/white), oral steroid use, calcium supplementation and vitamin $\mathrm{D}$ supplementation were based on self-report. Prevalent health conditions (diabetes, cardiovascular disease and depression) were assessed based on self-report and medication inventory. Physical activity in the preceding 7 days was assessed at baseline by questionnaire. $^{26} 27^{\circ}$

\section{Statistical analyses}

Differences in descriptive characteristics at baseline between participants with OLD, smoking controls, formerly-smoking controls and never-smoking controls were tested using ANOVA for continuous variables, $\chi^{2}$ for categorical variables and the Kruskal-Wallis test for continuous variables with skewed distributions. Post hoc comparisons were performed applying Bonferroni correction for multiple testing. Change in lung function could be calculated from a maximum of three time points only, hence per participant simple linear regression was applied to examine the yearly change (slope) in lung function. Subsequently, the mean slopes were tested between the study groups using ANOVA. The longitudinal data on body composition and physical functioning were analysed using multilevel regression models, allowing for the intercepts and slopes to vary between the four groups. This type of analysis takes into account the intraindividual correlation between repeated measurements and allows the inclusion of participants with incomplete data at follow-up. Therefore, no imputation of missing data was applied. The primary model included group 
Figure 2 Continued.
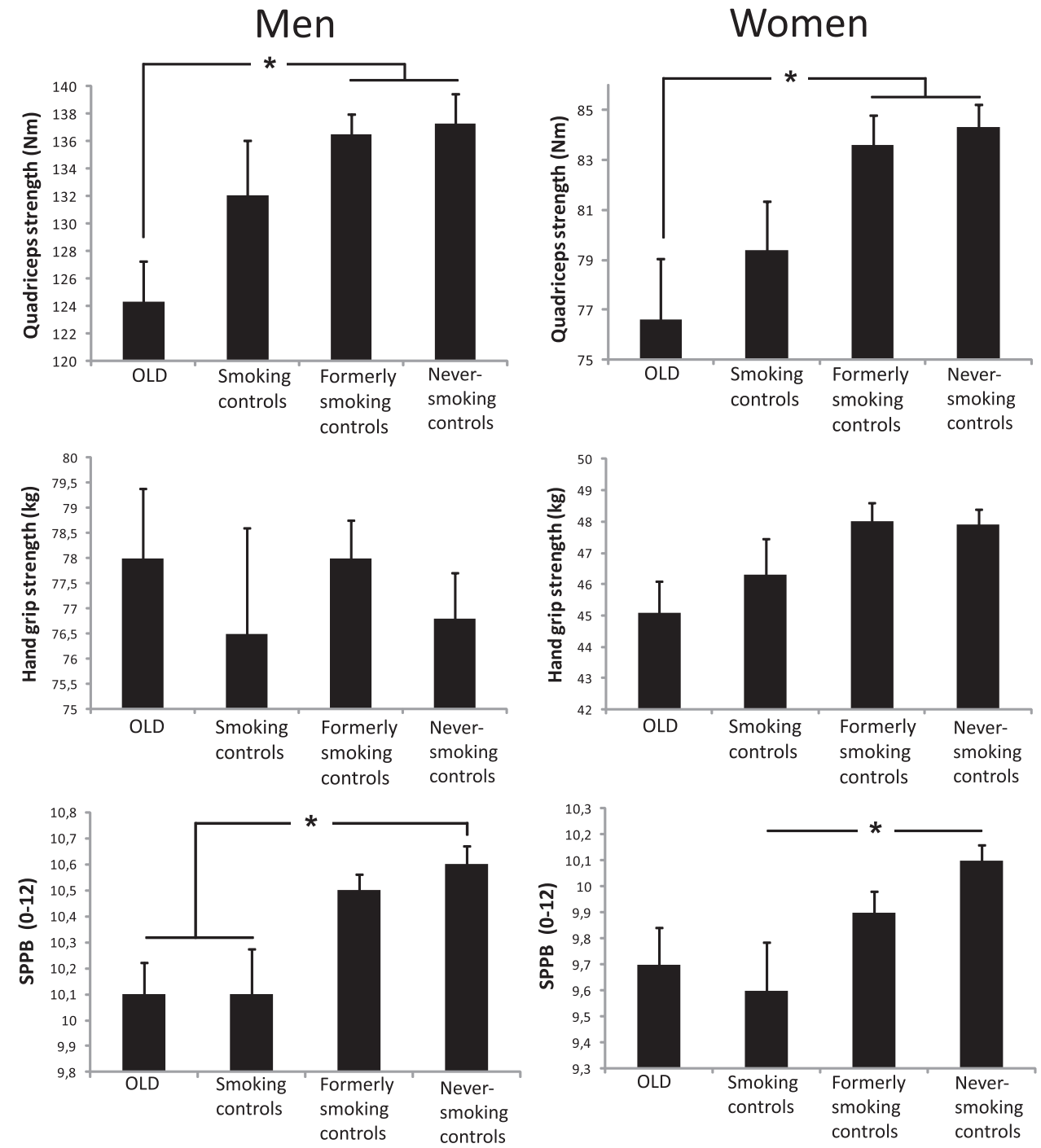

(OLD, smoking controls, formerly-smoking controls, neversmoking controls), age, race, clinic site, examination year (time), oral steroid use (yes/no), calcium supplementation (yes/no), vitamin D supplementation (yes/no), cardiovascular disease (yes/no), diabetes (yes/no), depression (yes/no), physical activity and an interaction term with time for all of these variables. The reported slopes are the coefficients of the interaction term group*time in which the never-smoking controls served as the reference group. In the second model, further adjustment was made for IL- 6, TNF- $\alpha$ and CRP and their interactions with time. There were no significant interaction effects between race and clinic site with the group variable on changes in body composition or physical functioning ( $p>0.05)$. Sample size considerations precluded examination of the effect of smoking status within the OLD group. The current analyses were performed for men and women separately because the gender distribution across the study groups was significantly different $(p<0.001)$, which was most pronounced in the formerly-smoking controls and never-smoking controls.

A small proportion of participants did not have measurements of body composition and physical functioning due to missing clinic visits while being alive. To examine the sensitivity of the results from the multilevel regression analyses to these missing observations, we used a joint model for the primary outcomes and missing probabilities. ${ }^{28}$ Statistical analyses were performed using PASW Statistics 17.0 (SPSS Inc). A p value $<0.05$ was considered statistically significant.

\section{RESULTS}

Baseline characteristics for men and women are presented in tables 1 and 2, respectively. The degree of airflow limitation in persons with OLD was mild $\left(\mathrm{FEV}_{1}>70 \%\right.$ predicted), moderate $\left(\mathrm{FEV}_{1} 50-70 \%\right.$ predicted) and severe ( $\mathrm{FEV}_{1}<50 \%$ predicted) in $32 \%, 38 \%$ and $30 \%$ of cases in men and in $36 \%, 41 \%$ and $23 \%$ of cases in women, respectively. The proportion of smokers, former-smokers and never-smokers in the OLD group was $63 \%$, $28 \%$ and $9 \%$ in men and $46 \%, 27 \%$ and $27 \%$ in women, respectively. Compared with never-smoking controls, the decline in $\mathrm{FEV}_{1}$ was lower in men with OLD ( $-38 \pm 6$ vs $-57 \pm 3 \mathrm{ml} /$ year, $\mathrm{p}=0.038)$ but not in women with OLD $(-33 \pm 5$ vs $-40 \pm 2 \mathrm{ml} /$ year, $\mathrm{p}=0.446$ ) (see table 1 in online supplement). The formerly-smoking controls had abstained from smoking for 25 (14) years. The prevalence of comorbid conditions was not different across the groups ( $p>0.05)$. Participants with OLD and smoking controls had comparable levels of physical activity to never-smoking controls ( $p>0.05)$. In men, those with OLD had increased CRP and IL- 6 levels, and smoking controls had higher IL-6 levels than never-smoking controls $(p<0.05)$. In women, smoking controls had higher IL-6 levels than never-smoking controls $(\mathrm{p}<0.05)$. 

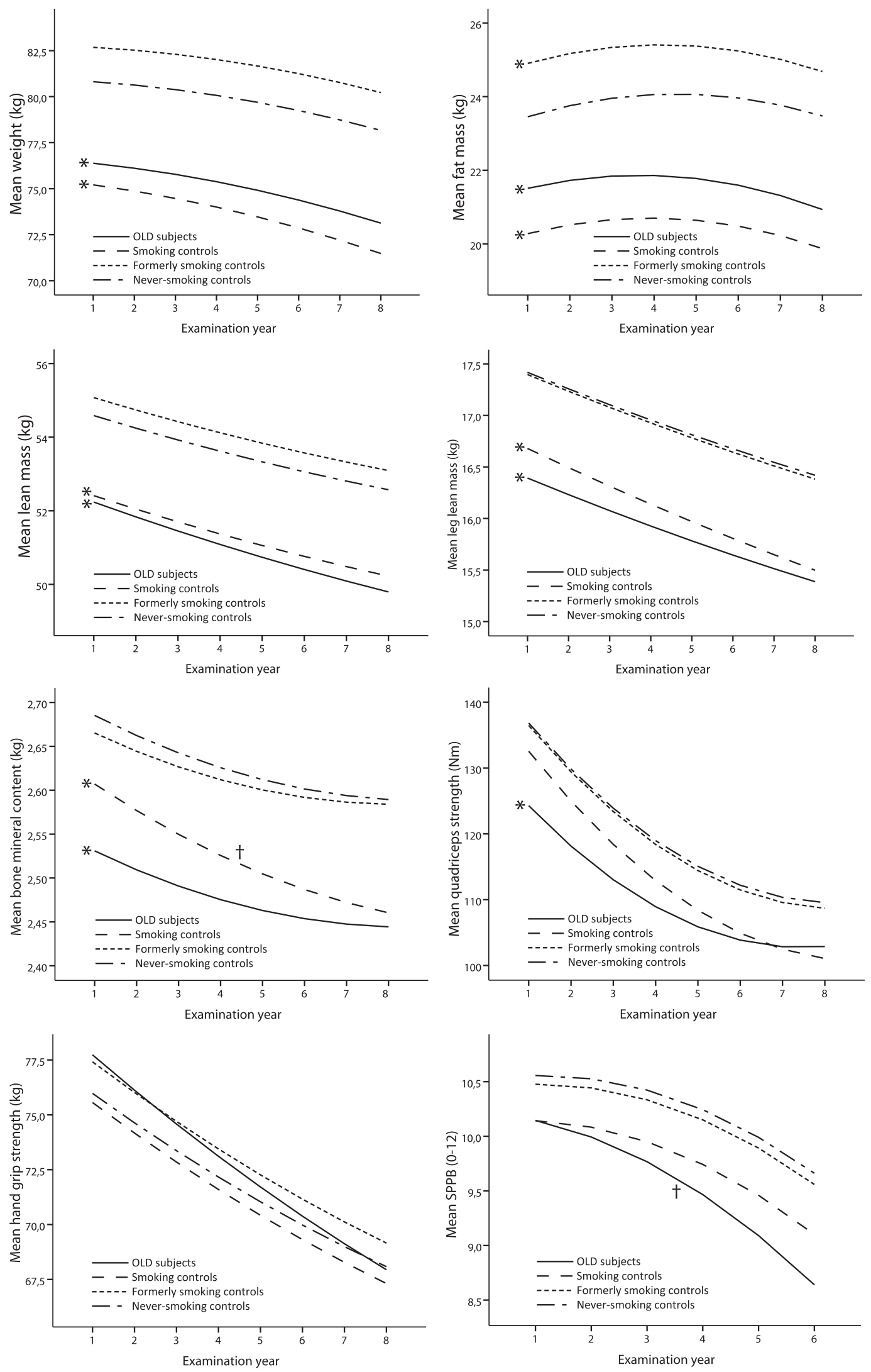

Figure 3 Longitudinal course of body composition and physical functioning according to obstructive lung disease and smoking status in men. Lines represent the mean predicted values adjusted for time, age, site, race, diabetes, cardiovascular disease, depression, physical activity, oral steroid use, calcium supplementation, vitamin $D$ supplementation, time ${ }^{2}$ age $\times$ time, race $\times$ time, site $\times$ time, diabetes $\times$ time, cardiovascular disease $\times$ time, depression $\times$ time and physical activity $\times$ time, oral steroid use $\times$ time, calcium supplementation $\times$ time and vitamin $D$ supplementation $\times$ time. *Intercept significantly different from never-smoking controls $(p<0.05)$. †Slope significantly different from never-smoking controls $(p<0.05)$. OLD, obstructive lung disease; SPPB, Short Physical Performance Battery. 

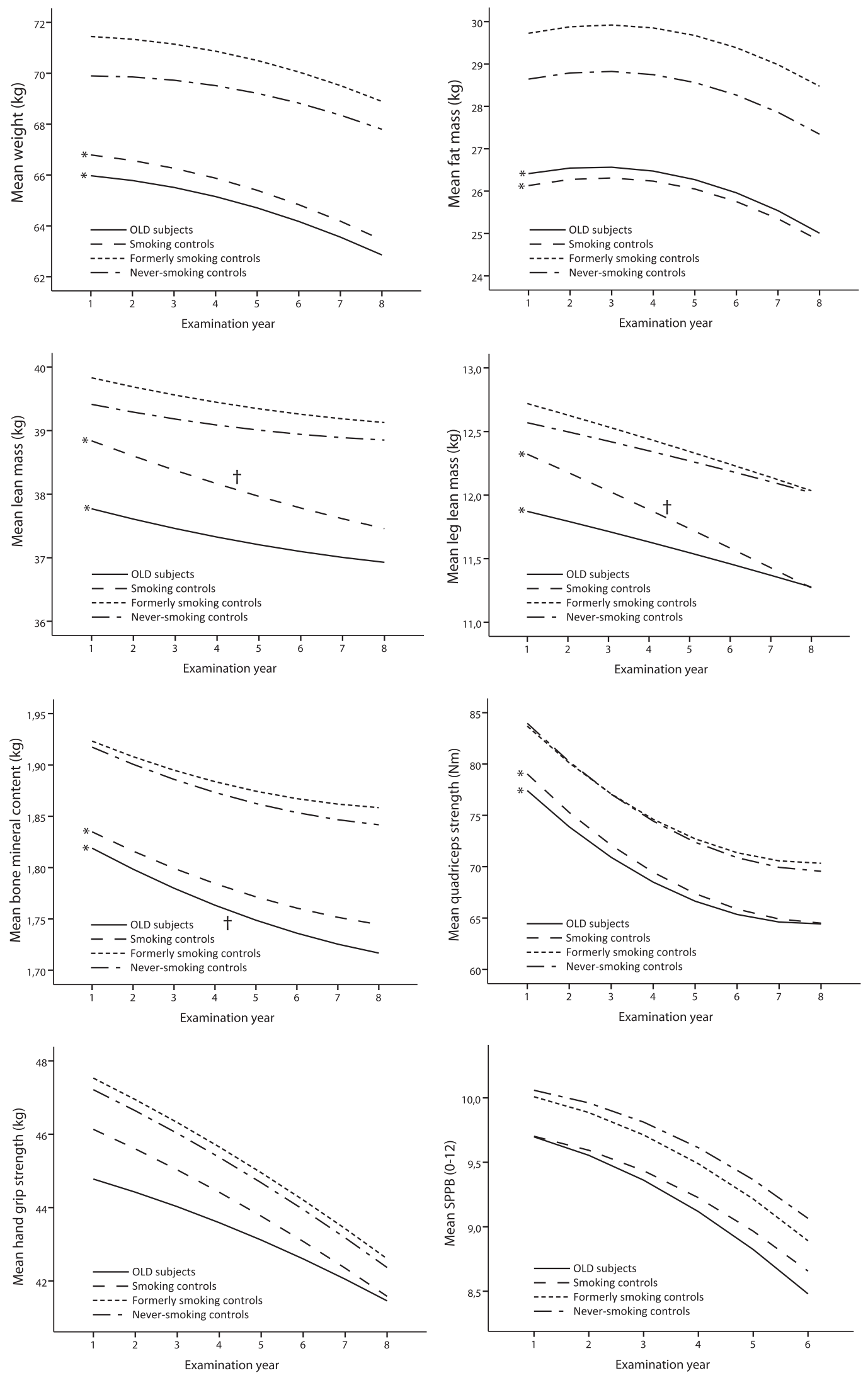

Figure 4 Longitudinal course of body composition and physical functioning according to obstructive lung disease and smoking status in women. Lines represent the mean predicted values adjusted for time, age, site, race, diabetes, cardiovascular disease, depression, physical activity, oral steroid use, calcium supplementation, vitamin D supplementation, time ${ }^{2}$ age $\times$ time, race $\times$ time, site $\times$ time, diabetes $\times$ time, cardiovascular disease $\times$ time, depression $\times$ time and physical activity $\times$ time, oral steroid use $\times$ time, calcium supplementation $\times$ time and vitamin $D$ supplementation $\times$ time. ${ }^{*}$ Intercept significantly different from never-smoking controls $(p<0.05)$. †Slope significantly different from never-smoking controls $(p<0.05)$. OLD, obstructive lung disease; SPPB, Short Physical Performance Battery. 
In both sexes, persons with OLD and smoking controls showed striking similarities with regard to lower measures of body composition and physical functioning compared with never-smoking controls (figure 2). In general, the adjusted intercepts from the multilevel models (figures 3 and 4 and corresponding tables 2 and 3 in the online supplement) showed similar findings to the baseline comparisons in figure 2 . While at baseline large differences were observed in body composition and physical functioning, the rates of longitudinal change of weight, fat mass, lean mass and strength were comparable between persons with OLD and never-smoking controls (all $\mathrm{p}>0.05$ ), except for the change in SPPB in men with OLD $(p=0.01)$ and $\mathrm{BMC}$ in women with OLD ( $\mathrm{p}=0.02)$. In smoking controls only lean mass declined faster in women $(p=0.03)$ and $B M C$ faster in men $(p=0.02)$ than in never-smoking controls, while the declines in weight and fat mass were comparable ( $p>0.05)$.

Further adjustment for baseline systemic cytokines resulted in a modest attenuation of several outcome measures (see tables 2 and 3 in online supplement). In particular, the lower baseline and faster decline of BMC in smoking control men (and women to a lesser extent) was explained by the cytokines for $26 \%$ and $25 \%$, respectively. The lower quadriceps strength in men and women with OLD was explained by the cytokines for $12 \%$ and $18 \%$, respectively.

In additional analyses, pack-years were added to model 1 but did not result in any major differences. Compared with neversmoking controls, formerly-smoking controls, smoking controls and participants with OLD had slightly higher probabilities of being missing during the 7-year follow-up period. However, the trajectories of the outcomes essentially remained the same when we adjusted for 'missingness' (data not shown). The percentage of participants alive at the year 8 visit was $62 \%, 66 \%, 77 \%$ and $85 \%$ for persons with OLD, smoking controls, formerly-smoking controls and never-smoking controls, respectively.

\section{DISCUSSION}

In this study we have shown striking similarities in body composition and physical functioning between older adult men and women with mild-to-moderate OLD and smokers with normal lung function. These were characterised by a markedly lower body weight, lean mass, fat mass, BMC and quadriceps strength compared with never-smoking controls. Interestingly, because longitudinal trajectories in the eighth decade of life were, to a large extent, comparable to those of their neversmoking controls, the large baseline differences persisted over a period of 7 years of follow-up. This suggests that a common insult related to smoking induced a divergent pattern earlier in life which may not uniformly persist into old age.

The unique design of the Health ABC Study enabled us to investigate for the first time the longitudinal pattern and progression of body composition changes and the decline in physical functioning simultaneously in persons with OLD and smokers without OLD in comparison with ageing effects in a never-smoking control group without OLD. Furthermore, by design of the Health ABC Study, none of the participants had functional limitations at baseline and, probably as a result of this selection, physical activity and the prevalence of comorbidity were comparable between the study groups. The Health ABC Study was therefore particularly of interest to examine the effects of smoking and OLD on body composition and physical functioning with ageing. Our results may, however, not be generalised to all older adults nor to patients with clinical COPD since study participants were aged 70-79 years and were wellfunctioning at baseline, and the OLD group was defined by lung function rather than a clinical COPD diagnosis. It therefore cannot be ruled out that our data might underestimate 'real' changes. Another strength of our study is that we carried out a sensitivity analysis to estimate the potential effect of missing observations on the observed trajectories. This effect was estimated to be small; however, this does not rule out the possibility that survival bias may have obscured our results. While we were unable to examine the effect of smoking status in the participants with OLD owing to sample size considerations, the results between the groups remained similar after further adjustment for pack-years, suggesting that the observed differences are independent of the quantity of smoking.

We found that the decline in $\mathrm{FEV}_{1}$ was lower in men with OLD than in their never-smoking controls. Because these data were generated from a relatively low number of follow-up lung function measures, we are careful in its interpretation, but it does suggest that longitudinal body composition and physical functioning trajectories in persons with OLD in our study are not related to a faster decline in $\mathrm{FEV}_{1}$.

In men with OLD but not in women, we found an accelerated decline in SPPB. This gender difference may be explained by a greater relative difference in leg lean mass and quadriceps strength between persons with OLD and never-smoking controls in men than in women. This is in line with a previous report showing that the relation between a lower fat-free mass and physical disability was more pronounced in men with COPD. ${ }^{29}$ A lower SPPB has been strongly related to subsequent disability and mortality, ${ }^{24}{ }^{30}$ and may thus be of clinical importance, particularly in men with OLD. Notably, despite a similar pattern of daily physical activity, quadriceps strength was much better able to discriminate between persons with OLD, smoking controls and never-smoking controls than hand grip strength. Women in the smoking control group had an accelerated decline in lean mass compared with never-smoking controls, which confirms previous cross-sectional data of a sarcopenic phenotype in older women who smoke. ${ }^{31}$

Systemic inflammation has been considered a key player in the extrapulmonary manifestations of $\mathrm{COPD},{ }^{5}$ and has been linked to muscle atrophy ${ }^{32}$ and bone demineralisation. ${ }^{33}$ In the present study we indeed confirmed the presence of mildly elevated circulating cytokines, particularly in men with OLD but also in smoking controls. After further adjustment for systemic inflammatory markers, we found little attenuation for the majority of outcome measures but systemic inflammatory markers did explain $11-26 \%$ of the observed baseline differences in BMC and $25 \%$ of the accelerated decline in men in the smoking control group.

The observation that smoking cessation is associated with weight gain is well known. ${ }^{34}$ While this effect is mainly considered a relatively short-term effect (months), ${ }^{35}$ former smokers in our study-who abstained from smoking for $\sim 25$ years-still showed a trend towards higher baseline weight which was mainly due to higher fat mass. Apart from fat mass, body composition and physical functioning in former smokers were comparable to that of never-smokers, suggesting a high recovery potential from smoking-induced losses. As higher body weight and lean mass have been associated with better survival in $\mathrm{COPD},{ }^{36}$ it needs to be determined whether this recovery potential is as functional in the state of COPD. We found higher CRP in women who formerly smoked and borderline significantly higher TNF- $\alpha$ in men who formerly smoked, which may be related to metabolic effects associated with fat abundance or altered fat distribution in obesity.

Although it was not part of our analyses, our data raise the possibility that low body and muscle mass may increase the risk 
of COPD development. In support of this, recent data from a large group of never-smokers from the Burden of Obstructive Lung Disease Study showed that the risk of COPD was significantly increased in those with a BMI $<20 \mathrm{~kg} / \mathrm{m}^{2}$, especially in women. ${ }^{37}$ In the case of smoking-induced COPD, however, it remains to be investigated whether a compromised body composition related to smoking contributes to the risk of COPD development. Our observation that the smoking controls had comparable pack-years smoked to participants with OLD and a similarly compromised body composition but no airflow obstruction indicates that it is not solely low body weight that increases the risk of COPD development, but suggests that other factors such as genetic susceptibility to, for example, emphysema and associated wasting are important.

In conclusion, our study shows that smoking is not only an important risk factor in the aetiology of OLD but also adversely affects body composition and physical functioning. The individual contributions of impaired weight gain and accelerated weight loss and a potential role for cytokinaemic stress associated with smoking remain to be studied in comparable future longitudinal studies in middle-aged persons.

Funding This study was supported by National Institute on Aging contracts N01-AG-6-2101, N01-AG-6-2103 and N01-AG-6-2106 and National Heart Lung and Blood Institute grant R01-HL-74104. This research was supported (in part) by the Intramural Research Program of the $\mathrm{NIH}$, National Institute on Aging. This study was performed within the framework of the Dutch Top Institute Pharma project T1-201, The Netherlands.

Correction notice This article has been corrected since it was published Online First. Figures 3 and 4 had incorrect footnote symbols.

Competing interests None.

Patient consent Obtained.

Ethics approval The Health ABC Study protocol was approved by the Institutional Review Boards of the clinical sites in Pittsburgh, Pennsylvania and Memphis, Tennessee.

Contributors BvdB, AK, HRG, TBH and AMWJS designed the study. BvdB performed the analyses, wrote the first draft of the manuscript and takes responsibility for the integrity of the manuscript. BY supervised the statistical analyses. AK, HRG, TBH and AMWJS supervised the study. BM, DCB, SBK, YL and ABN reviewed the manuscript.

Provenance and peer review Not commissioned; externally peer reviewed.

\section{REFERENCES}

1. Gooneratne NS, Patel NP, Corcoran A. Chronic obstructive pulmonary disease diagnosis and management in older adults. J Am Geriatr Soc 2010;58:1153-62.

2. Celli BR, MacNee W. Standards for the diagnosis and treatment of patients with COPD: a summary of the ATS/ERS position paper. Eur Respir $J$ 2004;23:932-46.

3. Chatila WM, Thomashow BM, Minai OA, et al. Comorbidities in chronic obstructive pulmonary disease. Proc Am Thorac Soc 2008;5:549-55.

4. Gan W0, Man SF, Senthilselvan A, et al. Association between chronic obstructive pulmonary disease and systemic inflammation: a systematic review and a metaanalysis. Thorax 2004;59:574-80.

5. Wouters EF, Reynaert NL, Dentener MA, et al. Systemic and local inflammation in asthma and chronic obstructive pulmonary disease: is there a connection? Proc Am Thorac Soc 2009;6:638-47.

6. Vestbo J, Prescott E, Almdal T, et al. Body mass, fat-free body mass, and prognosis in patients with chronic obstructive pulmonary disease from a random population sample: findings from the Copenhagen City Heart Study. Am J Respir Crit Care Med 2006:173:79-83.

7. Eisner MD, Iribarren C, Yelin EH, et al. Pulmonary function and the risk of functional limitation in chronic obstructive pulmonary disease. Am J Epidemiol 2008;167:1090-101.
8. Gosker HR, Zeegers MP, Wouters EF, et al. Muscle fibre type shifting in the vastus lateralis of patients with COPD is associated with disease severity: a systematic review and meta-analysis. Thorax 2007;62:944-9.

9. Graat-Verboom L, Wouters EF, Smeenk FW, et al. Current status of research on osteoporosis in COPD: a systematic review. Eur Respir J 2009;34:209-18.

10. Yende S, Waterer GW, Tolley EA, et al. Inflammatory markers are associated with ventilatory limitation and muscle dysfunction in obstructive lung disease in well functioning elderly subjects. Thorax 2006;61:10-16.

11. Scanlon PD, Connett JE, Wise RA, et al. Loss of bone density with inhaled triamcinolone in Lung Health Study II. Am J Respir Crit Care Med 2004;170:1302-9.

12. Oga T, Nishimura K, Tsukino M, et al. Exercise capacity deterioration in patients with COPD: Iongitudinal evaluation over 5 years. Chest 2005;128:62-9.

13. Oga T, Nishimura K, Tsukino M, et al. Longitudinal deteriorations in patient reported outcomes in patients with COPD. Respir Med 2007;101:146-53.

14. Habraken JM, van der Wal WM, Ter Riet G, et al. Health-related quality of life and functional status in end-stage COPD: longitudinal study. Eur Respir J 2011:37:280-8.

15. Koster A, Visser M, Simonsick EM, et al. Association between fitness and changes in body composition and muscle strength. J Am Geriatr Soc 2010;58:219-26.

16. Fulop T, Larbi A, Witkowski JM, et al. Aging, frailty and age-related diseases. Biogerontology 2010;11:547-63.

17. Montes de Oca M, Loeb E, Torres SH, et al. Peripheral muscle alterations in nonCOPD smokers. Chest 2008;133:13-18.

18. Wust RC, Morse $\mathrm{Cl}$, de Haan A, et al. Skeletal muscle properties and fatigue resistance in relation to smoking history. Eur J Appl Physiol 2008;104:103-10.

19. Tanni SE, Pelegrino NR, Angeleli AY, et al. Smoking status and tumor necrosis factor-alpha mediated systemic inflammation in COPD patients. J Inflamm (London) 2010; 7:29

20. Levitzky YS, Guo CY, Rong J, et al. Relation of smoking status to a panel of inflammatory markers: the Framingham offspring. Atherosclerosis 2008;201:217-24.

21. Hankinson JL, Odencrantz JR, Fedan KB. Spirometric reference values from a sample of the general U.S. population. Am J Respir Crit Care Med 1999; 159:179-87.

22. Mehrotra N, Freire AX, Bauer DC, et al. Predictors of mortality in elderly subjects with obstructive airway disease: the PILE score. Ann Epidemiol 2010;20:223-32.

23. Guralnik JM, Simonsick EM, Ferrucci L, et al. A short physical performance battery assessing lower extremity function: association with self-reported disability and prediction of mortality and nursing home admission. J Gerontol 1994;49:M85-94.

24. Guralnik JM, Ferrucci L, Simonsick EM, et al. Lower-extremity function in persons over the age of 70 years as a predictor of subsequent disability. $N$ Engl J Med 1995;332:556-61.

25. Koster A, Stenholm S, Alley DE, et al. Body fat distribution and inflammation among obese older adults with and without metabolic syndrome. Obesity (Silver Spring) 2010:18:2354-61.

26. Koster A, Patel KV, Visser M, et al. Joint effects of adiposity and physical activity on incident mobility limitation in older adults. J Am Geriatr Soc 2008;56:636-43.

27. Ainsworth BE, Haskell WL, Whitt MC, et al. Compendium of physical activities: an update of activity codes and MET intensities. Med Sci Sports Exerc 2000;32(Suppl 9):S498-504.

28. Ghosh P, Tu W. Assessing sexual attitudes and behaviors of young women: a joint model with nonlinear time effects, time varying covariates, and dropouts. J Am Stat Assoc 2008;103:1496-507.

29. Schols AM, Broekhuizen R, Weling-Scheepers CA, et al. Body composition and mortality in chronic obstructive pulmonary disease. Am J Clin Nutr 2005;82:53-9.

30. Melzer D, Lan TY, Guralnik JM. The predictive validity for mortality of the index of mobility-related limitation: results from the EPESE study. Age Ageing 2003;32:619-25

31. Castillo EM, Goodman-Gruen D, Kritz-Silverstein D, et al. Sarcopenia in elderly men and women: the Rancho Bernardo study. Am J Prev Med 2003;25:226-31.

32. Langen RC, Schols AM, Kelders MC, et al. Muscle wasting and impaired muscle regeneration in a murine model of chronic pulmonary inflammation. Am J Respir Cell Mol Biol 2006;35:689-96

33. McLean RR. Proinflammatory cytokines and osteoporosis. Curr Osteoporos Rep 2009; 7:134-9.

34. Filozof C, Fernandez Pinilla MC, Fernandez-Cruz A. Smoking cessation and weight gain. Obes Rev 2004;5:95-103.

35. Cropsey KL, McClure LA, Jackson DO, et al. The impact of quitting smoking on weight among women prisoners participating in a smoking cessation intervention. Am J Public Health 2010;100:1442-8.

36. Schols AM, Slangen J, Volovics L, et al. Weight loss is a reversible factor in the prognosis of chronic obstructive pulmonary disease. Am J Respir Crit Care Med 1998:157:1791-7.

37. Lamprecht B, McBurnie MA, Vollmer WM, et al. COPD in never smokers: results from the population-based burden of obstructive lung disease study. Chest 2011:139:752-63. 